\title{
3D Visualization Monitoring and Early Warning of Surface Deformation in Subsidence Area Based on GIS
}

\author{
Lei Gao, ${ }^{1}$ Yuanwen Song $\mathbb{D}^{2},{ }^{2}$ and Bo Zhao ${ }^{1}$ \\ ${ }^{1}$ Department of Geology and Jewelry, Lanzhou Resources and Environment Voc-tech College, Lanzhou 730021, China \\ ${ }^{2}$ Department of Safety Engineering, Lanzhou Resources and Environment Voc-tech College, Lanzhou 730021, China
}

Correspondence should be addressed to Yuanwen Song; songyw@lzre.edu.cn

Received 27 October 2020; Revised 9 December 2020; Accepted 17 December 2020; Published 7 January 2021

Academic Editor: Wei Wang

Copyright $\odot 2021$ Lei Gao et al. This is an open access article distributed under the Creative Commons Attribution License, which permits unrestricted use, distribution, and reproduction in any medium, provided the original work is properly cited.

Due to the large-scale mining of mineral resources, the surface strata in many areas have collapsed and even developed into deformation and subsidence. Based on the conventional geotechnical deformation monitoring technology, the surface deformation prediction and disaster caused by the conventional geotechnical deformation monitoring technology can be avoided. In this paper, based on GIS, combined with the analysis of surface settlement, the surface settlement, slope value, curvature deformation value, horizontal displacement, and corresponding horizontal deformation formula are comprehensively analyzed and studied. In order to make the surface deformation visualization and realize the high approximation processing with the subsidence area, this paper innovatively introduces the $3 \mathrm{D}$ visualization settlement data analysis and realizes the calculation result analysis and corresponding retrieval multiple visualization in the subsidence area depth prediction process. On this basis, the prediction data of subsidence area can be optimized and analyzed so as to master the efficient and accurate law of surface deformation. In the experimental part, a mine is taken as the experimental object, and the $3 \mathrm{D}$ visual monitoring processing is carried out. In this paper, the main method to prevent electromagnetic leakage of the computer system is the source suppression method. The source suppression method solves the problem fundamentally by reducing or eliminating the emission of computer electromagnetic leakage source. In the actual experiment, the effect of this method is very effective. The experimental results show that the prediction results and corresponding early warning accuracy of the system are significantly improved compared with the traditional scheme, which provides practical significance for disaster prevention and corresponding environmental impact assessment.

\section{Introduction}

With the continuous development of new energy technology, traditional energy and other nonrenewable energy have declined, but from the global energy share point of view, traditional energy such as coal, natural gas, and so on still occupy a very important position $[1,2]$. The excessive exploitation of traditional energy not only has a great impact on the natural ecological environment but also brings a lot of hidden natural disasters to people, such as long-term surface subsidence, landslide, deformation, and slide, which will seriously threaten the collapse area and the safety of human life around the collapse area this may even cause serious surface disasters [3-6]. As the most serious problem of traditional mine pit, the corresponding monitoring and early warning means mainly focus on repeated level monitoring, total station measurement technology, GPS measurement technology, and traditional point distribution monitoring technology. This kind of technology is relatively flexible, and the corresponding detection range is relatively high, but its corresponding detection accuracy is limited by computer information processing technology At the same time, the corresponding data analysis cannot achieve visualization processing [7-10]. Based on this, how to realize the efficient, accurate, and visual detection and early warning of surface deformation in subsidence area is the key to solve and implement.

The surface deformation corresponding to the subsidence area has brought great impact on human beings and nature. Based on this, a large number of researchers and relevant research institutions have studied and analyzed the 
corresponding early warning and monitoring of surface deformation [11]. German and other European scholars were the first to predict and analyze the surface deformation of subsidence area. In the continuous research and analysis, they developed the subsidence calculation rules. The main core of the method is to apply the stochastic process equation to the loose body mechanics. The rock mass movement and the corresponding elements are regarded as the random movement of the loose element, which lays the foundation for the subsidence calculation The analysis is mainly achieved by finite element analysis. This scheme has certain advanced and correctness, but its corresponding engineering calculation is too large, and the corresponding resource waste is serious $[12,13]$. Based on this, the relevant scholars analyzed and improved the settlement calculation rule and proposed the surface deformation prediction scheme based on the influence function rule. It made full use of the basic properties and flexibility of the corresponding influence function, modified the corresponding original node function to generate an asymmetric function, and then realized the calculation and prediction of surface deformation in the subsidence area These schemes have certain flexibility, but they still have the disadvantage of huge calculation amount $[14,15]$. Based on the mechanical equilibrium conditions and corresponding geometric contact conditions, relevant Asian scholars analyzed and studied the surface deformation, mainly through Fourier transform and the corresponding inversion formula to solve the corresponding data. This scheme overall has a low resource occupancy rate and a relatively high accuracy, but this scheme is accurate for large-scale collapse area calculation accuracy problem [16-18]. The corresponding scholars in Japan have vectorized the surface corresponding to the corresponding subsidence area. The vector principle and the corresponding number of application layers are used to establish the corresponding vertical and horizontal components of the surface deformation prediction formula, thus forming the surface deformation model. This scheme has certain novelty, but its corresponding prediction accuracy still needs to be improved. Further analysis and discussion $[19,20]$ of other research schemes, such as time function scheme under surface deformation and elastic mechanics analysis scheme under surface deformation should be carried out [21-24]. On the whole, there are relatively few research studies on the visualization level of the current research scheme, but it has obvious value and significance for improving the accuracy of surface deformation prediction and interaction.

Based on the above analysis, in order to solve the problem of visualization of surface deformation in subsidence area and the prediction accuracy and monitoring accuracy of surface natural disasters, this paper will combine it with surface subsidence analysis based on GIS, and based on this, the surface subsidence coefficient, inclination value, curvature deformation value, horizontal displacement, and horizontal deformation coefficient are comprehensively analyzed and studied [25-28]. In order to make the surface deformation visualization corresponding to the collapse area, this paper innovatively introduces the $3 \mathrm{D}$ visualization subsidence data analysis to realize the calculation result analysis and corresponding retrieval multiple visualization in the process of subsidence area depth prediction [29-35]. Based on this, this paper can realize the optimization analysis of the prediction data of the subsidence area and then grasp the efficient and accurate law of surface deformation. In the experimental part, a mine pit is taken as the experimental object, and the three-dimensional visual monitoring is carried out. The experimental results show that the prediction results and corresponding early warning accuracy of the system are significantly improved compared with the traditional scheme, which provides practical significance for disaster prevention and corresponding environmental impact assessment.

This paper is organized as follows. Section 2 of this paper will carry out visualization processing and analysis of the degree of surface deformation based on GIS system and establish the corresponding digital terrain model of surface subsidence area based on this. Section 3 of this paper will focus on the design of 3D visualization monitoring and early warning system of surface deformation based on GIS. Section 4 will carry out the system test. Finally, Section 5 gives the conclusion and prospects.

\section{GIS-Based Analysis and Processing of Subsidence Area}

In this paper, the technology foundation used in dealing with $3 \mathrm{D}$ visualization technology of surface deformation is GIS. The corresponding frame diagram of the whole system is shown in Figure 1. It mainly applies the technology of resource management, regional division, land monitoring, and corresponding auxiliary decision making. As shown in Figure 1, we can see the main core algorithm of the GIS system for monitoring and early warning of surface deformation. It lies in the 3D visualization technology based on the GIS system.

The GIS in the map is combined with the analysis of surface subsidence to comprehensively analyze the surface subsidence, tilt value, curvature deformation value, horizontal movement, and the corresponding horizontal deformation formula. In order to make the surface deformation visualization corresponding to the collapse area, this paper innovatively introduces the $3 \mathrm{D}$ visualization subsidence data analysis to realize the calculation result analysis and corresponding retrieval multiple visualization in the process of subsidence area depth prediction.

\subsection{Surface Visualization Technology Processing Based on GIS.} In this paper, ArcGIS processing platform is selected when selecting GIS processing platform, and its corresponding characteristics mainly focus on the following points: the system is highly scalable; the system integration is high; and the system security is relatively high. The corresponding GIS-related mainstream components are shown in Table 1. It can be seen from the table that it mainly includes five mainstream components: ArcGIS desktop software, ArcSDE data path, ArcIMS path, ArcGIS service part, and corresponding ArcGIS Engine part. It can be seen from the table 


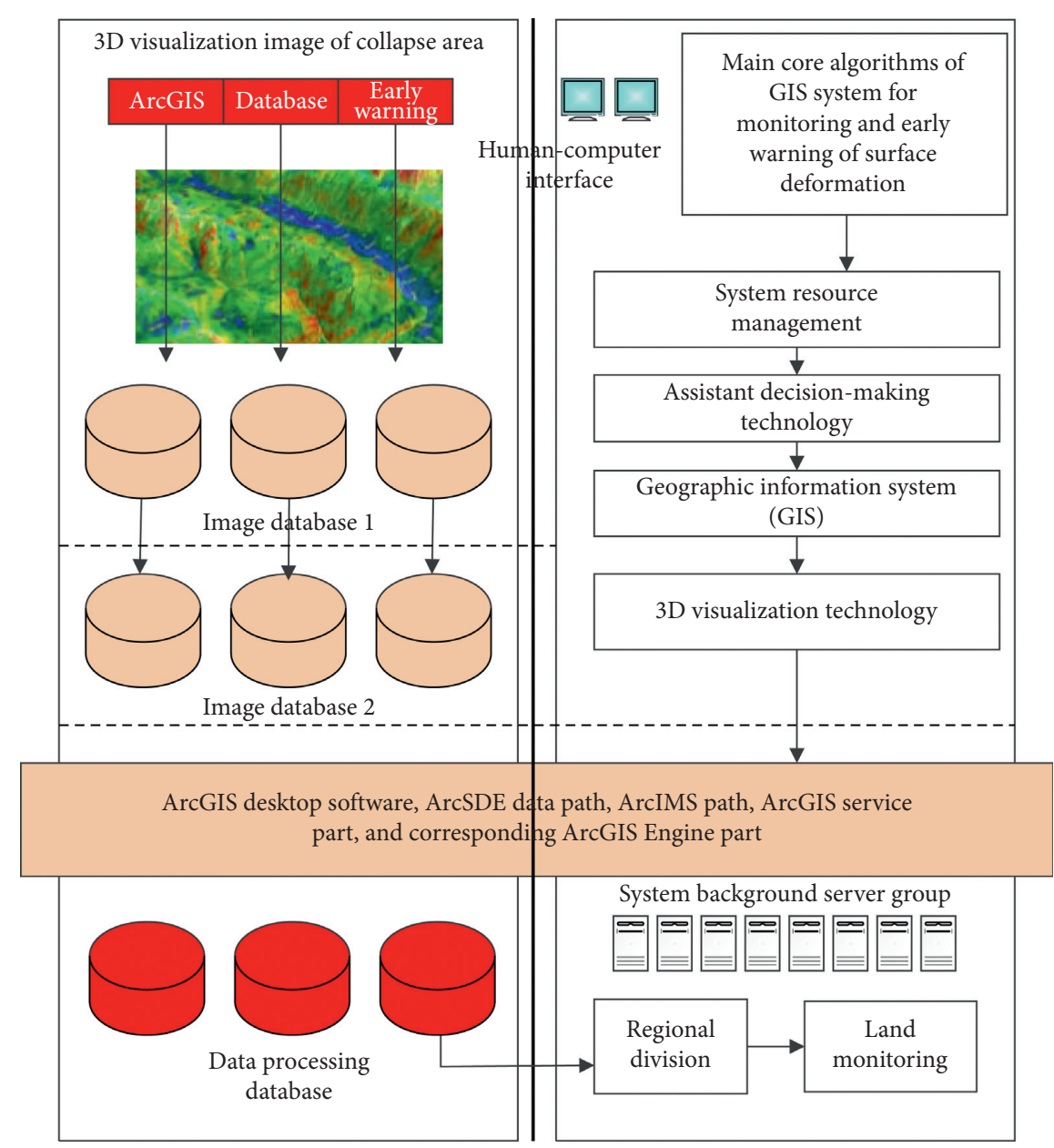

FIGURE 1: Framework of 3D visualization early warning and monitoring system for surface deformation based on GIS.

TABle 1: Details of mainstream parts of ArcGIS platform.

\begin{tabular}{lc}
\hline ArcGIS system & Details one time smoothing prediction value \\
\hline $\begin{array}{l}\text { ArcGIS desktop } \\
\text { software }\end{array}$ & It is mainly the unification of the corresponding extension module of general structure and development \\
ArcSDE data path & It is mainly used for data channel between GIS and database \\
$\begin{array}{l}\text { ArcIMS pathway } \\
\text { ArcGIS service part }\end{array}$ & It is mainly used to build enterprise-level GIS application platform with centralized management and supports \\
multiple users
\end{tabular}

Surface fracture zone height treatment and overburden transverse strain diagram processing.

that the corresponding GIS path is more critical, which is mainly used for the data channel between GIS and database.

2.1.1. Pretreatment of Monitoring Data. In fact, the main means of monitoring data is optical fiber monitoring technology. By selecting representative points and then arranging according to certain rules, interpolation algorithm is mainly used in actual data processing. The main purpose of the corresponding interpolation algorithm is to obtain more data points; at the same time, the values corresponding to the selected known samples are diffused according to a certain method, and based on this, all other points are given a relatively reasonable prediction value. Finally, the reconstruction of continuous change plane in three-dimensional space or two-dimensional space is realized by such algorithm. As shown in Figure 2, the closer the weight of the corresponding points in Figure 2 is determined by the distance between the corresponding points of the interpolation method in Figure 2. In order to establish the vertical strain diagram of overburden rock, the data processing and format conversion of optical fiber strain data are needed in the preprocessing stage. In the actual processing process, the basic properties of strain data points are mainly sorted, 


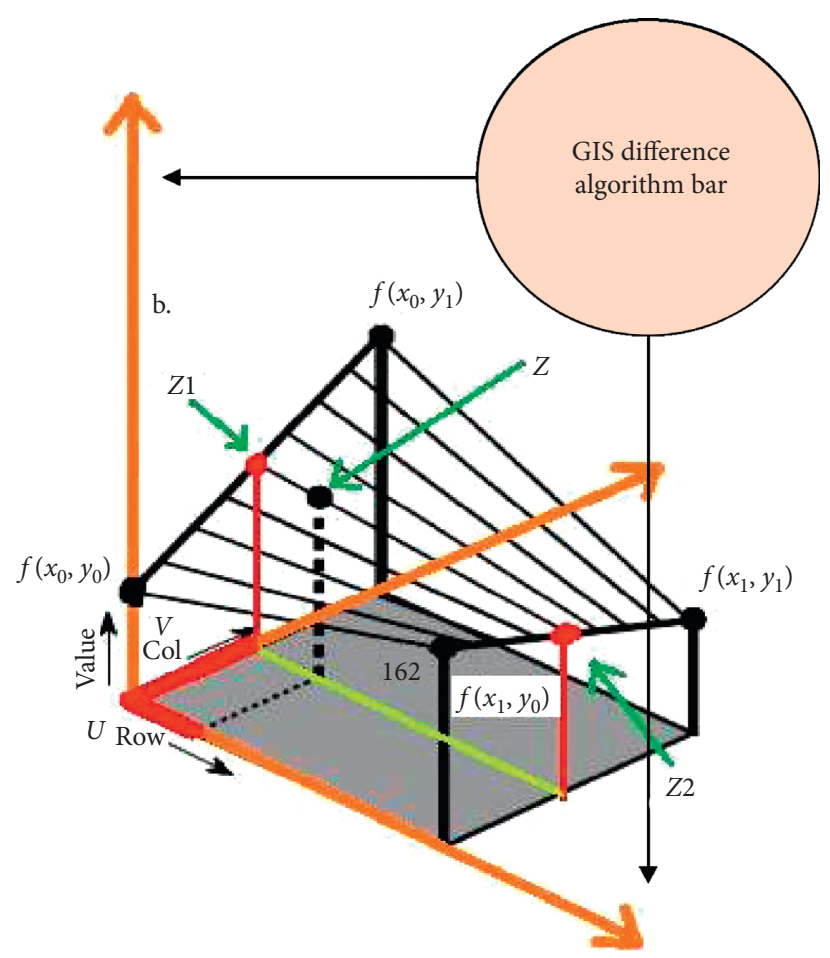

FIGURE 2: GIS surface deformation monitoring and early warning interpolation algorithm architecture.

including three coordinates; the corresponding abscissa represents the value of optical fiber in the model length direction, and the corresponding ordinate represents the optical fiber in the model height. The corresponding $z$ coordinate represents the strain value of the fiber.

\subsubsection{Treatment of Vertical Strain Diagram of Overburden} Rock. In this part, the strain data measured by pushing the vertical optical fiber are processed and analyzed, and the vertical strain diagram of overburden is drawn according to the different values of the distance between working face and cut hole. The processing diagram of the distance from the corresponding working face to the cutoff is shown in Figures 3-5. It can be seen from the figure that the abscissa of the corresponding vertical strain diagram of overburden represents the total length of the whole surface model, and the corresponding vertical axis represents the height of the surface model, which mainly reflects the corresponding change law of the whole overburden under different surface deformation intensities. The corresponding isoline in the map has been drawn. One side of the corresponding isoline is positive, which represents the stretching area, while the other side of the corresponding isoline becomes negative, which represents the compression area.

It can be seen from Figures 4 and 5 that when the corresponding working face is close to the cutting hole, the corresponding small amount of artificial surface mining has little influence on the stability of the whole surface, and the corresponding overburden deformation is also very small. When the distance between the corresponding working face and the incision increases, the corresponding surface deformation will be more serious, which will seriously reduce the stability of the whole surface. In addition, it can be seen from Figures 4 and 5 that the distance point where the degree of surface deformation drops sharply is about $1 \mathrm{~m}$, and the corresponding strength and thickness of rocks at this distance are relatively the highest. The deformation corresponding to stress transfer is relatively small, which has a certain control effect on the deformation of the whole surface covering layer. Therefore, the fault at this distance should belong to the surface overburden and key strata.

2.1.3. Height Treatment of Surface Fracture Zone. In the actual surface mining process, the corresponding mineral resources are constantly taken out from the surface, the corresponding overburden stress balance is constantly damaged, and the corresponding surface stress redistribution occurs, which makes the stress continuously accumulate, resulting in the corresponding displacement and even deformation and fracture of the strata above the goaf. Therefore, based on the above analysis, it is very important to detect the height of surface fracture zone. In fact, when the corresponding overburden rocks are deformed, the corresponding optical fiber sensors and corresponding overburden rocks will also have corresponding coordinated deformation. The corresponding expression is shown in formula (1). It can be seen from formula (1) that the corresponding $M$ represents the diameter of the optical fiber sensor, the corresponding $E$ represents the elastic modulus of the optical fiber sensor, and the corresponding $\mathrm{d} m / \mathrm{d} n$ represents the corresponding strain gradient.

$$
M=\left(\frac{E \cdot D}{4}\right) \frac{\mathrm{d} m}{\mathrm{~d} n} .
$$

In order to verify the correlation between the surface overburden deformation and the sensor deformation data, Figures 6 and 7 show the surface deformation curve 


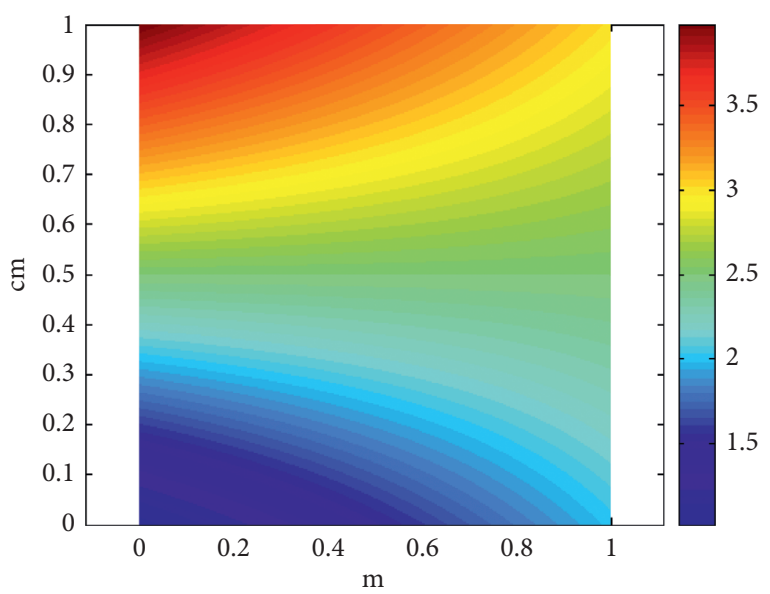

Figure 3: Treatment map of distance between surface working face and cut hole in subsidence area $(d=30 \mathrm{~cm})$.

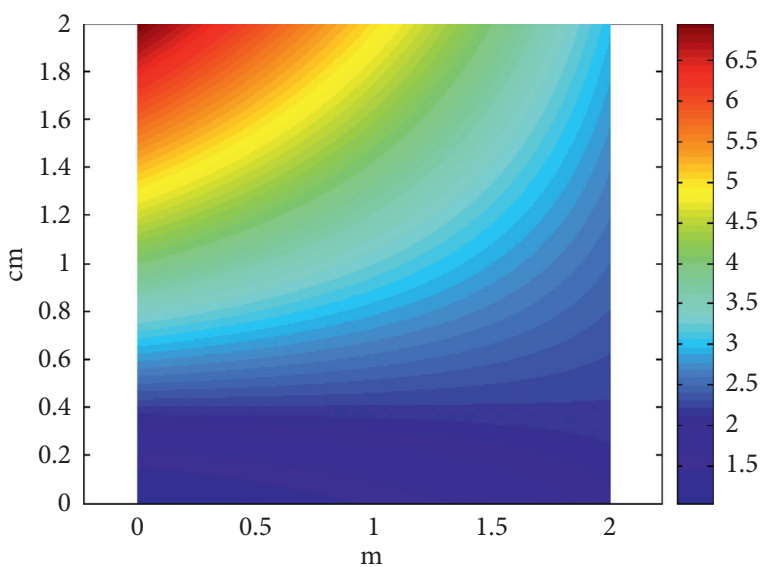

FIgURE 4: Treatment map of distance between surface working face and cut hole in subsidence area $(d=50 \mathrm{~cm})$.

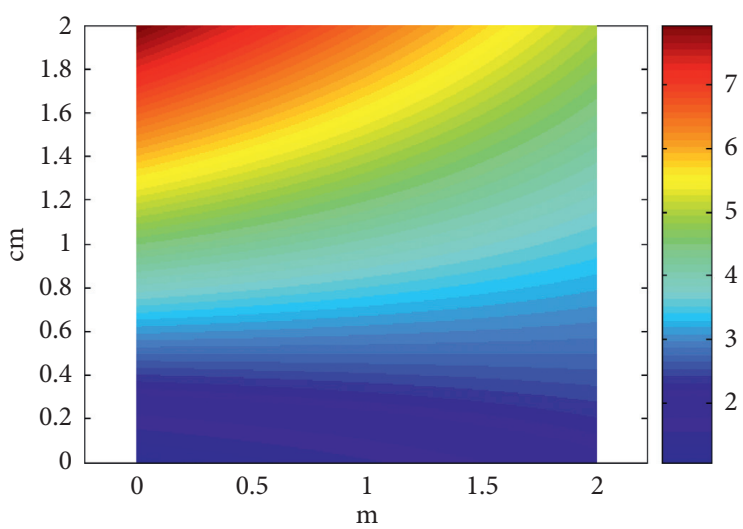

FIGURE 5: Processing map of distance between surface working face and cut hole in subsidence area $(d=80 \mathrm{~cm})$.

corresponding to the different heights of the corresponding surface fracture zone when the distance between the working face and the cut hole is constant. It can be seen from the figure that when the distance between the surface working face and the cut is small, and the shape of the surface will change accordingly, resulting in cracks on the surface. The relationship between the height of the fracture zone is not strong, but when the distance between the corresponding 

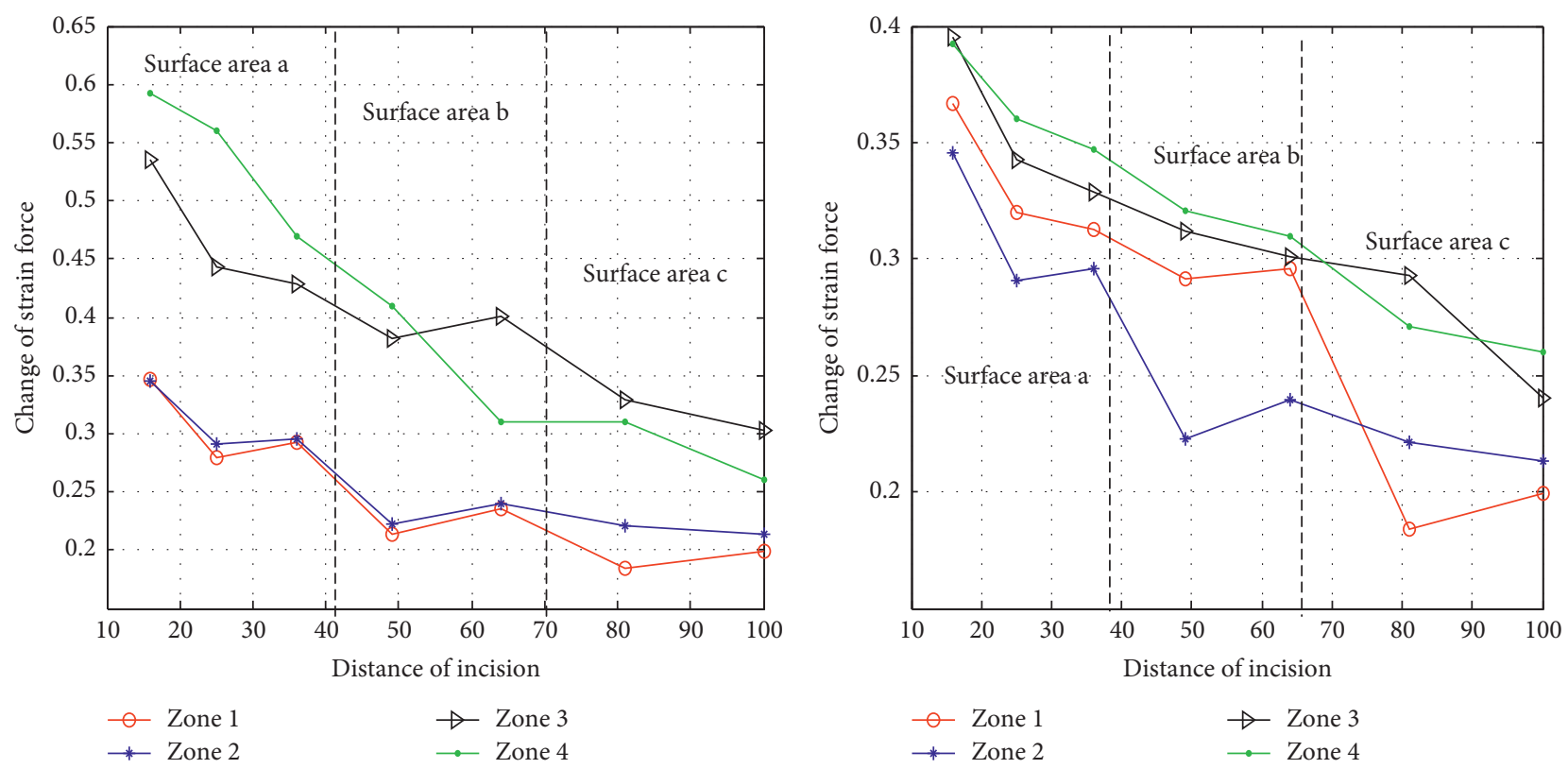

(a)

(b)

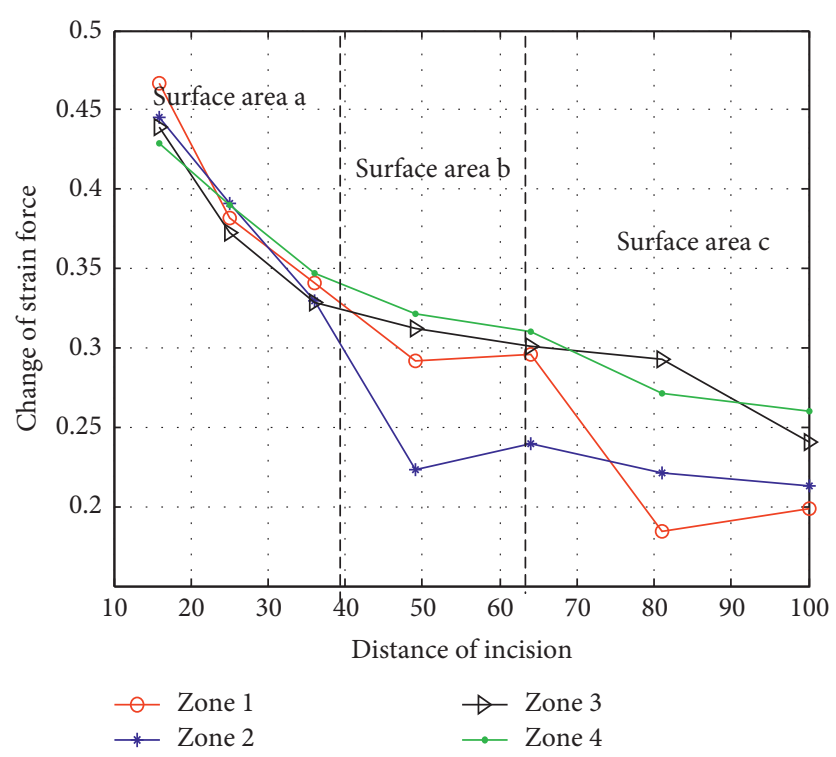

(c)

FIGURE 6: Variation curve of surface deformation corresponding to different heights of crack zone on site surface (30 cm). (a) Division 1 . (b) Division 2. (c) Division 3.

working face and the incision is large, the corresponding surface deformation will be directly proportional to the height of the surface fracture zone.

2.1.4. Lateral Strain Diagram Processing of Overburden. In this part, the strain data measured by pushing the transverse optical fiber are processed and analyzed, and the transverse strain diagram of overburden is drawn according to the different values of the distance between the working face and the cut hole. Figures 8 and 9 are used to process the distance between the corresponding working face and the incisor. It can be seen from the figure that the abscissa of the corresponding overburden transverse strain diagram represents the total length of the whole surface model, and the corresponding vertical axis represents the height of the surface model, which mainly reflects the corresponding change law of the whole overburden under different surface deformation intensities. The corresponding isoline in the map has been drawn. One side of the corresponding isoline is positive, which represents the stretching area, while the other side of the corresponding isoline becomes negative, which represents the compression area. From the figure, we can draw the following basic qualitative conclusions: when the corresponding working face is close to the cut off hole, the corresponding small amount of artificial surface mining has little influence on the stability of the whole surface, and the 


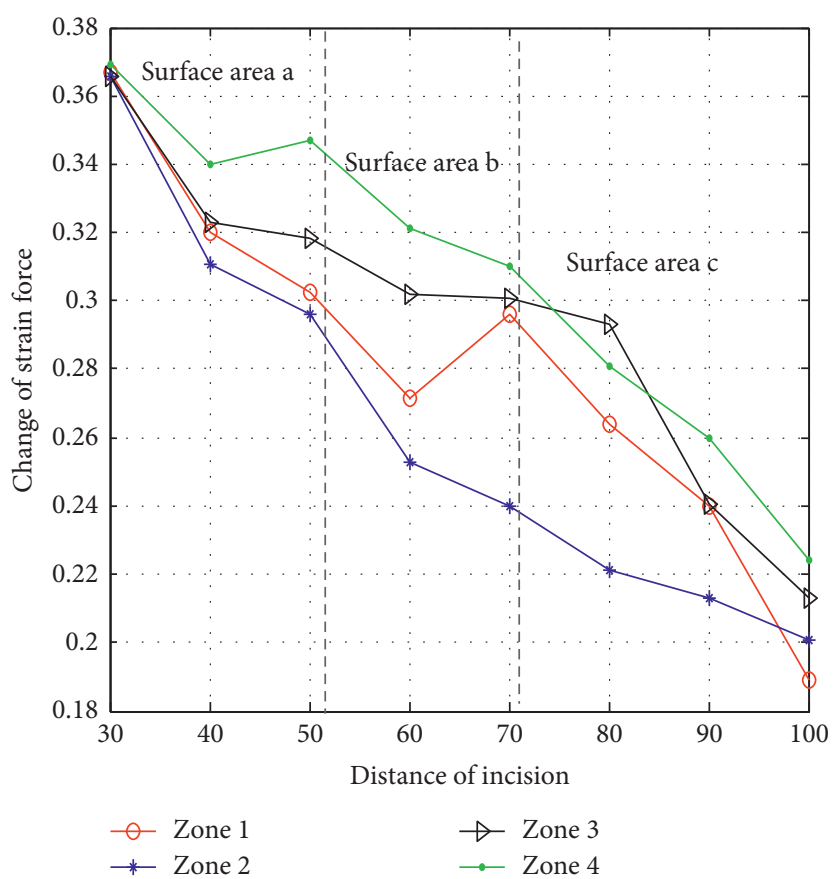

(a)

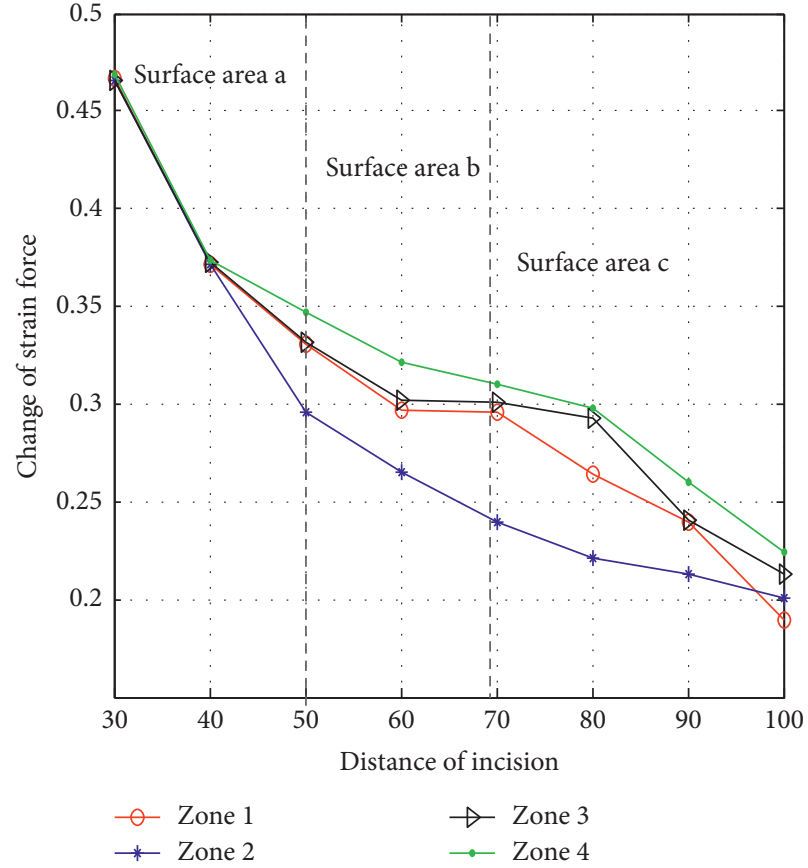

(b)

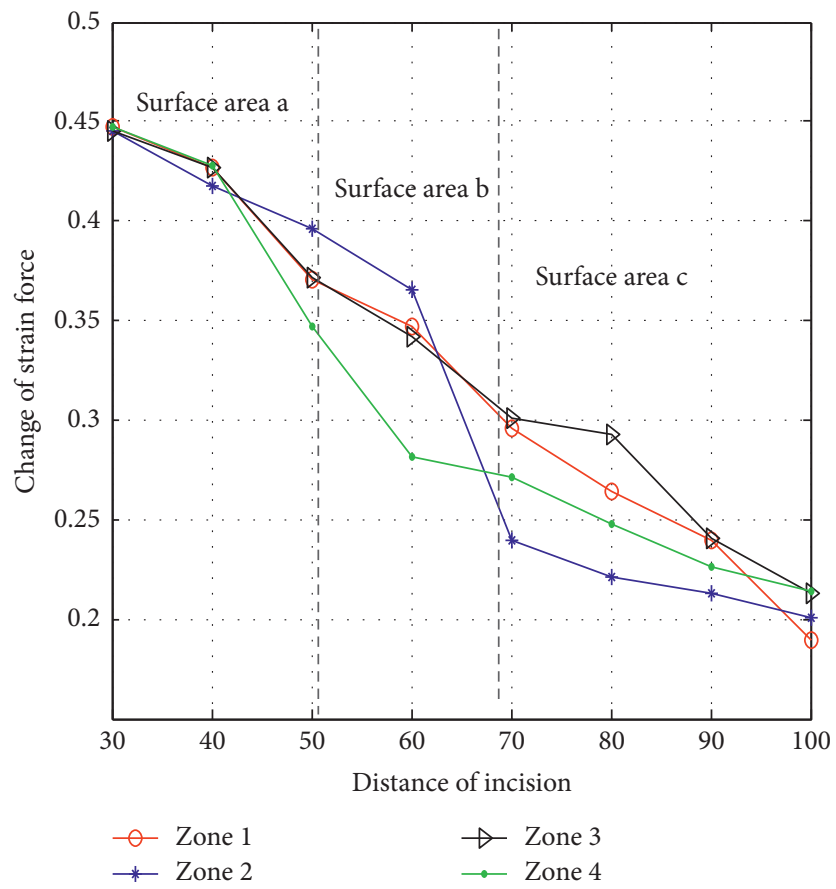

(c)

FIGURE 7: Variation curve of surface deformation corresponding to different heights of crack zone on site surface (60 cm). (a) Division 1. . (b) Division 2. (c) Division 3.

corresponding amount of deformation of overburden is very small. When the distance between the corresponding working face and the cut is increasing, the corresponding surface deformation will be more severe, which will seriously reduce the stability of the whole surface. In addition, it can be seen from the figure that the distance point of the cliff type decline of the degree of surface deformation is about $70 \mathrm{~cm}$. The corresponding strength of the rock at this distance is relatively the highest, and the corresponding thickness is also large. The deformation corresponding to the stress transmission is relatively small, which has a certain control effect on the deformation of the whole surface overburden. Therefore, the fault at this distance should belong to the surface overburden and the key rock layers. 

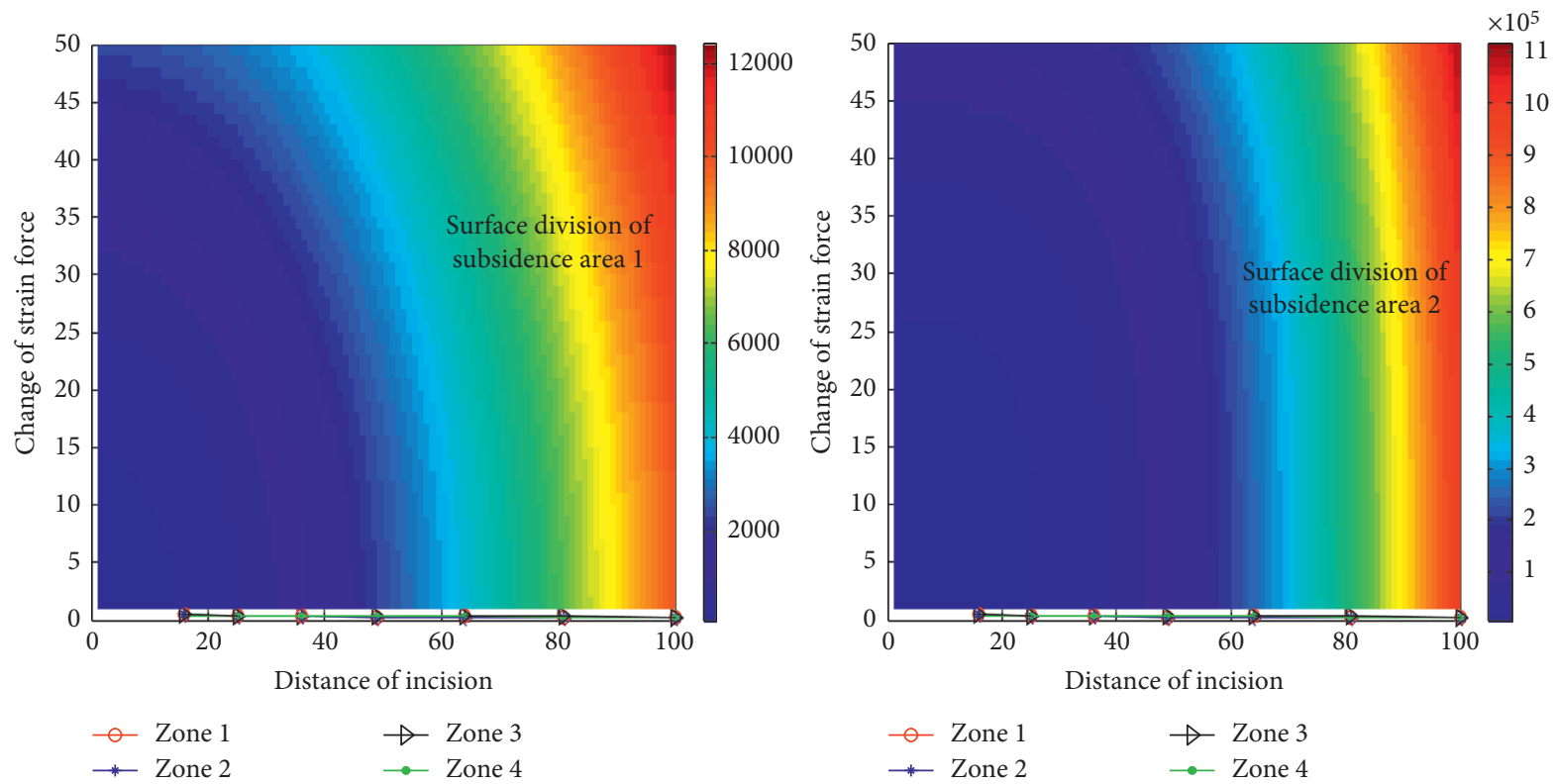

FIgURE 8: Treatment map of distance between surface working face and cut hole in subsidence area $(d=50 \mathrm{~cm})$.
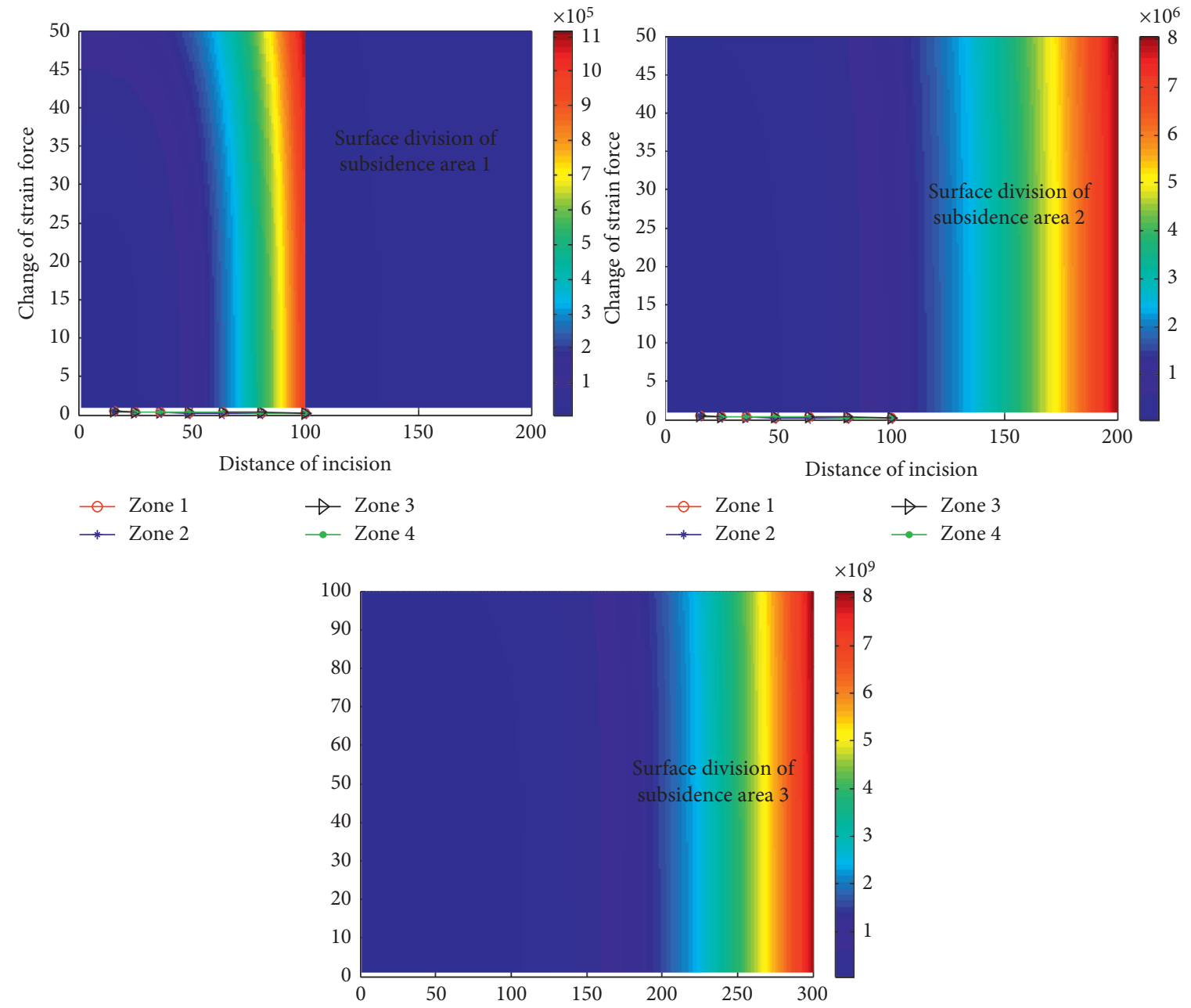

FIgURe 9: Processing map of distance between surface working face and cut hole in subsidence area $(d=80 \mathrm{~cm})$. 
2.2. Establishment and Analysis of Digital Model of Surface Deformation in Subsidence Area. Based on the GIS-based surface model analysis and visualization processing in Section 2.1 above, this section will establish the corresponding digital model to further process the corresponding surface visualization. It mainly includes the following four parts: GIS data acquisition, related data conversion, GIS data preprocessing analysis, and corresponding digital modeling. The corresponding processing flowchart is shown in Figure 10. It can be seen from Figure 10 that the most important link is the construction of irregular network, which mainly uses the corresponding GIS original data as the grid points of digital modeling. Based on this, it will not lose the accuracy of the original data and will retain the original key terrain features. At the same time, it can be seen from the map that the corresponding irregular shape has stronger adaptability.

\section{Design of 3D Visualization Monitoring and Early Warning System of Surface Deformation Based on GIS}

Based on the principle analysis of the second section above, this section mainly designs the corresponding three-dimensional visualization monitoring and early warning system. The corresponding system block diagram is shown in Figure 11. The actual system design mainly follows the principles of practicability, reliability, visualization, and completeness. From the system design framework, we can see that the core design module is the visualization module of surface deformation monitoring in subsidence area. In this module, ADO is used to establish the corresponding data connection so that the corresponding database of the whole system can be accessed, deleted, and added. The database processing level of the corresponding whole system is mainly based on SQL database processing, which mainly deals with the spatial data of the whole system and the corresponding graphic data, and at the same time, it mainly applies the database system to manage the attribute data.

The corresponding development language and the overall function of the system are as follows:

(1) Data acquisition module: in this part, through the digital processing of a large number of data, pictures and videos in the collapse area, the digital conversion of images, the corresponding data, tables, and table input are processed. The corresponding images include the topographic and geological images of the subsidence area, the surface deformation layer excavation plan, etc.

(2) Data processing module: in this part, the data with similar properties are uniformly encoded, and the collected images and data are separately stored. After preprocessing the corresponding original data, the derived database can be generated. The corresponding database includes rock movement calculation parameter database, mining subsidence control parameter database, and the database required by the digital terrain model.
(3) Data query and update service: this part is mainly to solve the subsidence management and provide information services for decision making. It can make reasonable subsidence protection strategy according to the data and information of the whole system at different times so as to make more effective use of land and comprehensive management of land. The system has the function of real-time updating spatial data and attribute data of collapse area in policy query operation.

(4) Calculation part of deformation part in collapse area: this part is mainly a lot of calculation. It is mainly to calculate the subsidence value corresponding to the collapse area, including the subsidence, inclination, curvature calculation, horizontal movement, and horizontal deformation of the collapse area.

(5) Human-computer interaction function of the system: this part mainly considers the humancomputer interaction part of the whole system. The system has good user interface automatic drawing function and corresponding report function. At the same time, the system should also have the function of text output. At the same time, in addition to the actual prediction calculation, the whole system can also realize the corresponding deformation calculation and object movement prediction calculation of buildings, structures and corresponding railways, highways, and conventional roads above the collapse area. For the corresponding deformation calculation level, the basic data acquisition and corresponding basic format input are mainly considered.

In the corresponding system component technology level, the system adopts component GIS technology, which mainly divides the modules of each part of the system into several corresponding controls, and each control completes different functions. The corresponding controls and the corresponding controls and noncontrols are mainly integrated by visual software development tools to form the corresponding GIS application. The component technology of this system is mainly to improve the production efficiency of the whole system.

In the whole system debugging and operation process, we need to put each design function into the actual debugging link. In this stage, we need to further combine it with the development goal of this paper, aiming at the corresponding system overall structure and each function module, through the corresponding program debugging, data acquisition, database establishment, and system debugging to complete the corresponding system overall development work. In the actual survey process, it needs to start from the bottom layer, mainly including data input, surface 


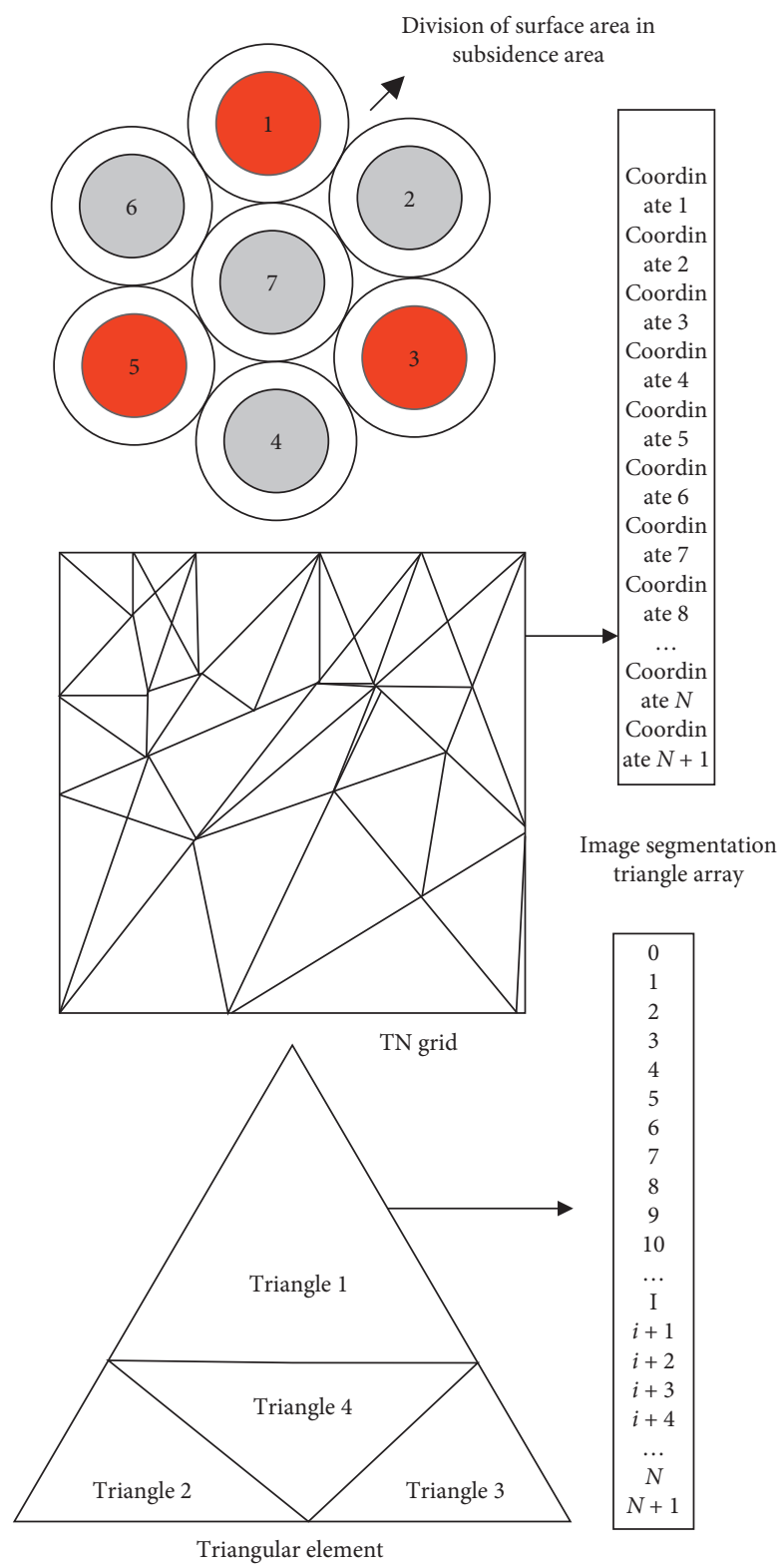

FIGURE 10: Framework of digital terrain model construction in subsidence area.

subsidence data calculation, 3D visualization display of surface subsidence data in subsidence area, and realization of data conversion interface. After the actual debugging, the corresponding submodules are gathered together to form the overall function module of the system so as to complete the overall development effect of the system.

In the maintenance and evaluation of the system, the system can provide maintenance personnel with necessary adjustment and modification mechanism. The corresponding system maintenance and adjustment mainly refers to the corresponding staff continuously adjusting the corresponding system parameters in GIS after putting it into operation so as to adapt to the changes of environment and other elements and to ensure the normal operation of the whole system. The corresponding system evaluation is to evaluate, test, and analyze the performance of the GIS system, including economic indicators, performance indicators, and corresponding management indicators.

\section{Validation Analysis}

Based on the above theoretical analysis, this paper carried out an experimental verification for a mine, and two evaluation indexes of the experiment are determined: three-dimensional visualization index of surface deformation and risk coefficient index of surface subsidence. The corresponding GIS evaluation platform uses ArcGIS platform. 

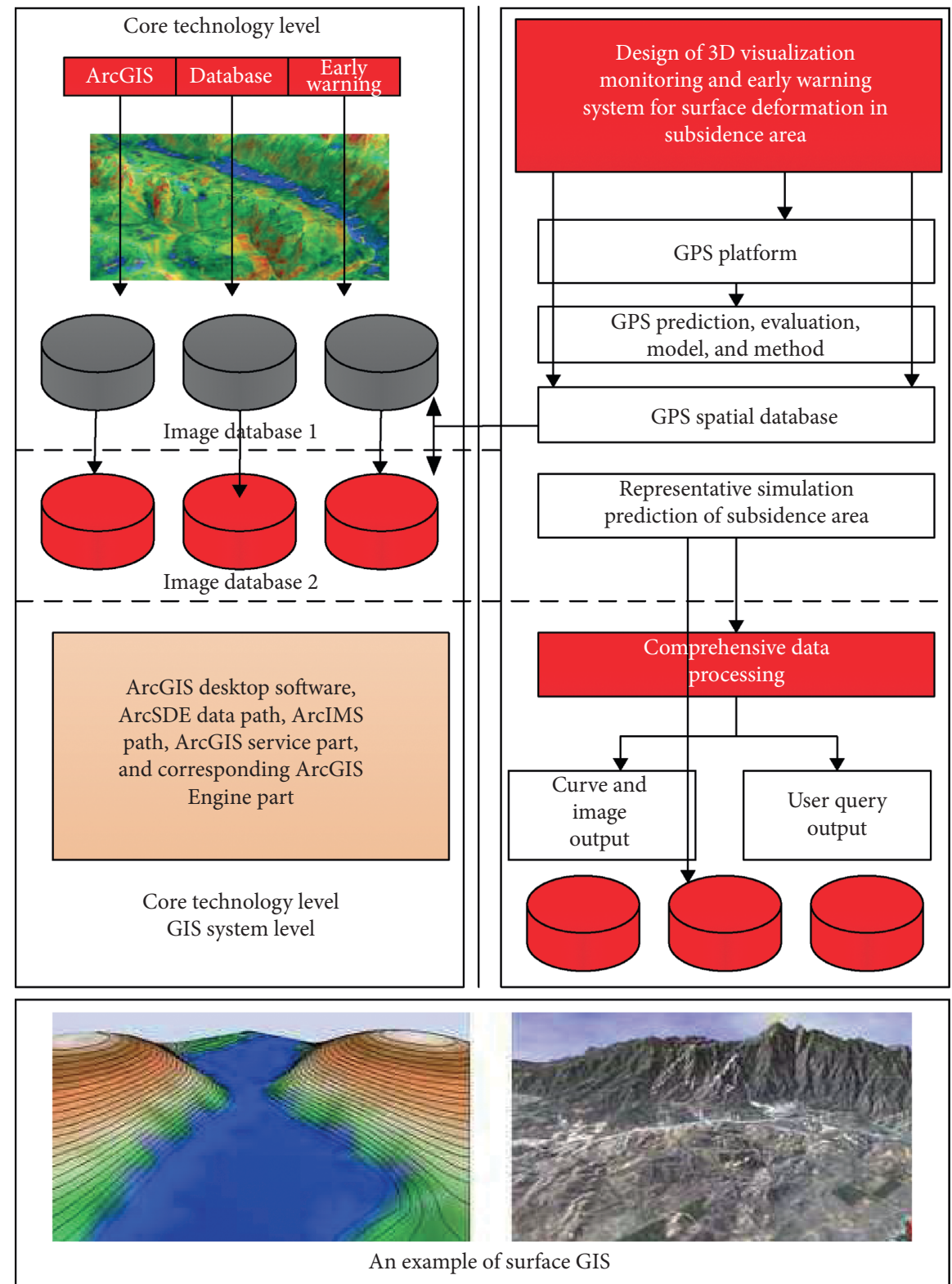

FIGURE 11: Design of 3D visualization monitoring and early warning system for surface deformation in subsidence area.

4.1. Experimental Comparison of $3 D$ Visualization Degree of Surface Deformation. The corresponding experimental environment is mainly controlled in the same area and different surface subsidence environments, and the corresponding contrast test indexes are mainly concentrated in three-dimensional settlement depth, settlement level trend, and corresponding settlement depth trend. The same software and approximate parameters are used in the corresponding settlement analysis and data acquisition analysis. The experiment is mainly to compare the three-dimensional visualization technology in this paper under different surface conditions. The corresponding three-dimensional views of the experiment are shown in Figures 12-14. It can be seen from the figures that the $3 \mathrm{D}$ global view of surface subsidence, horizontal movement cloud map of strike, and corresponding horizontal movement of dip can be seen based on GIS Cloud image, in which the corresponding boundary is the coordinate axis. Through the cognition of $3 \mathrm{D}$ viewable surface, it can be found that the corresponding map can obviously feed back the physical quantities of mine pit surface movement and deformation, which provides a reference for surface deformation and early warning in subsidence area.

4.2. Accuracy of Early Warning for Possible Danger of Surface Subsidence. The experiment is mainly to verify the threedimensional visualization of early warning and monitoring compared with the traditional early warning and monitoring in the accuracy of the comparative experiment. The actual area of the mine is divided into five parts, and the corresponding data of the actual area are shown in the map (Figure 15). 


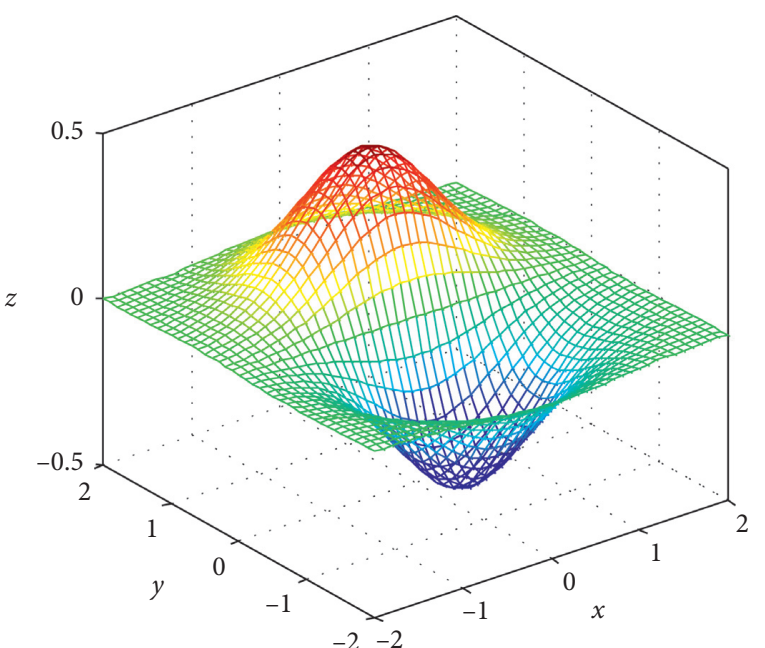

(a)

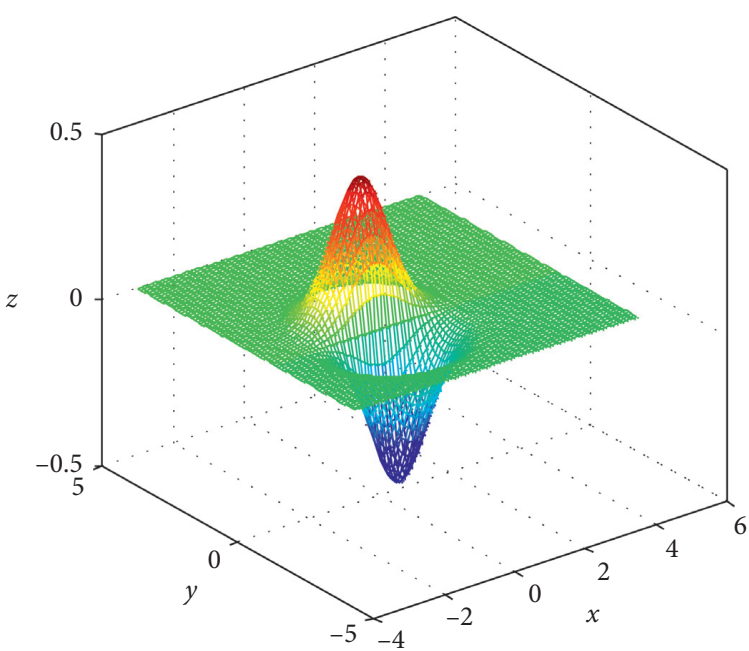

(b)

FIGURE 12: 3D visualization global map of surface in subsidence area.

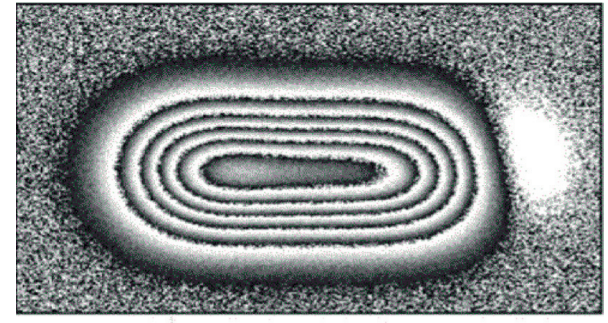

(a)

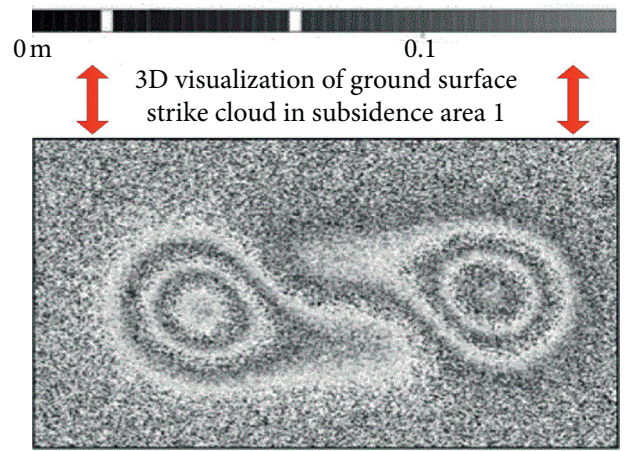

(b)

0.2

0.3

FIGURE 13: 3D visualization of ground surface strike cloud in subsidence area.

Based on the data of the mine one year ago and the corresponding three-dimensional visualization map, the system in this paper is used for early warning. At the same time, the warning results of the traditional system and the actual collapse data of the mine after one year are compared. The corresponding experimental results are shown in Tables 2-7. From the tables, we can see that the corresponding five areas are divided into regions. The surface deformation visualization based on GIS in this paper has obvious advantages in early warning accuracy. 


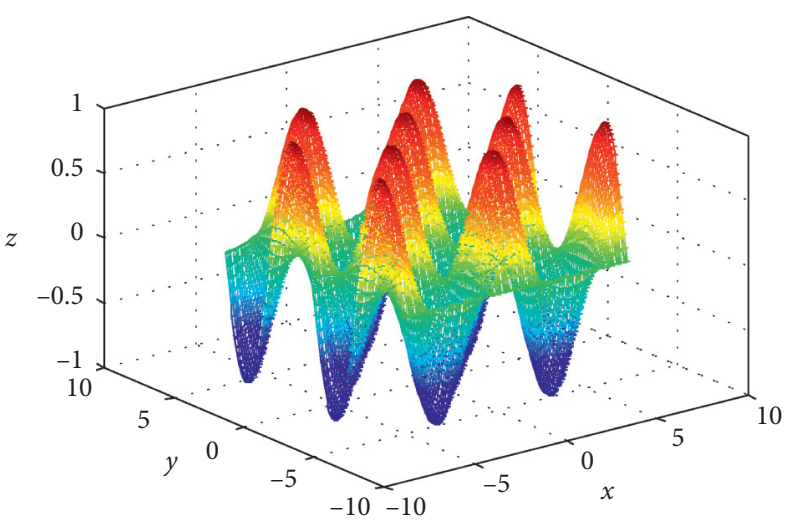

(a)

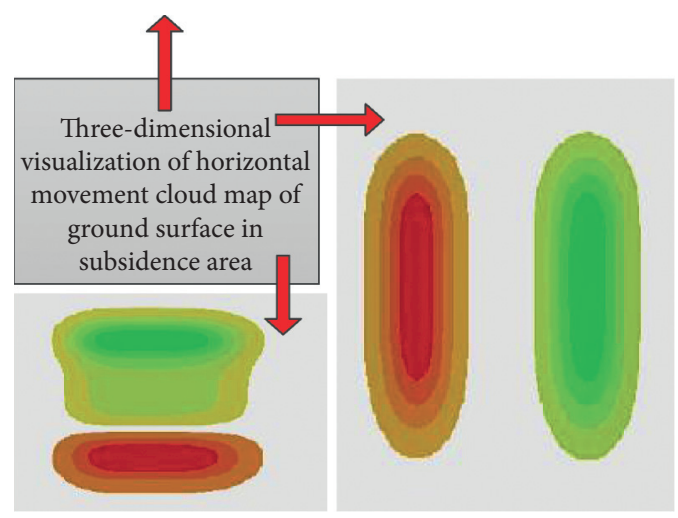

(b)

FIgURE 14: Three-dimensional visualization of horizontal movement cloud map of ground surface in subsidence area. (a) Global map of surface deformation. (b) Horizontal and vertical details.

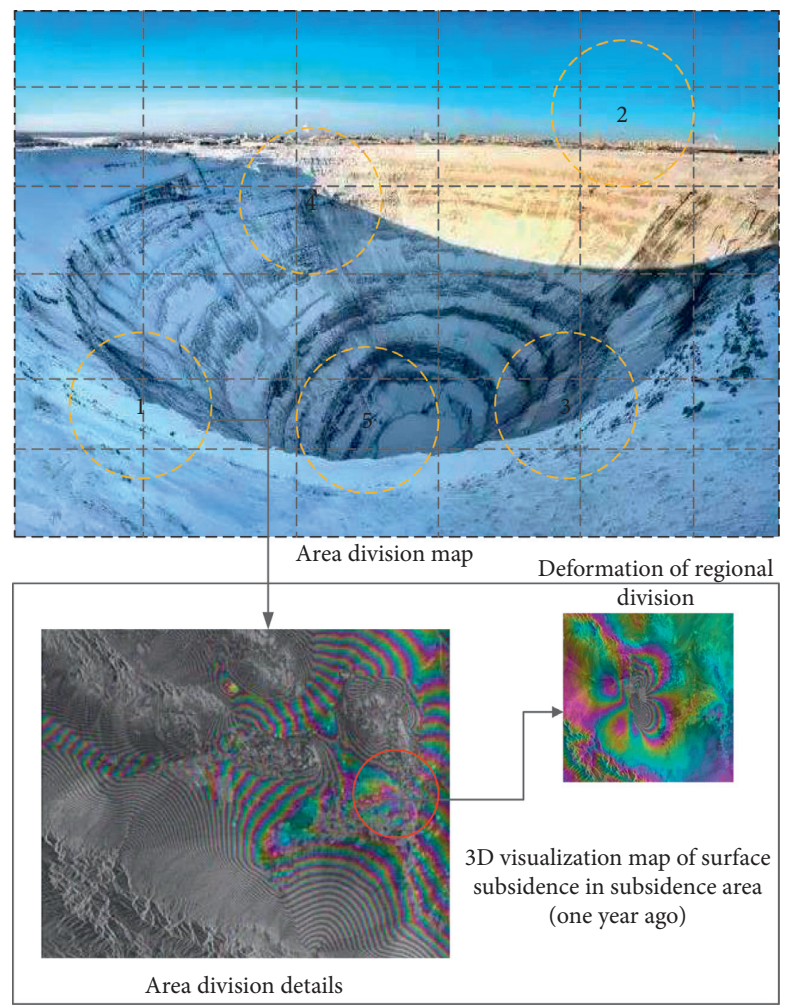

FiguRE 15: 3D visualization map of surface subsidence in subsidence area (one year ago).

TABLE 2: Comparison of experimental data in area 1.

\begin{tabular}{lccc}
\hline Index coefficient & The early warning system used in this paper & Traditional early warning system & Actual data \\
\hline Transverse axis displacement 1 & 3.712 & 3.521 & 3.703 \\
Longitudinal axis displacement 1 & 3.404 & 2.985 & 3.339 \\
Z-axis displacement 1 & 6.225 & 4.822 & 6.119 \\
Total displacement 1 & 5.344 & 3.421 & 5.321 \\
Transverse axis displacement 2 & 3.602 & 2.985 \\
Longitudinal axis displacement 2 & 3.404 & 6.092 \\
Z-axis displacement 2 & 6.225 & 4.822 & 3.603 \\
Total displacement 2 & 5.344 & 3.221 & 3.339 \\
Transverse axis displacement 3 & 3.312 & 2.585 & 6.119 \\
Longitudinal axis displacement 3 & 3.134 & 5.692 & 3.321 \\
Z-axis displacement 3 & 6.315 & 5.922 \\
Total displacement 3 & 5.944 & 3.098 \\
\hline
\end{tabular}


TABLE 3: Comparison of experimental data in area 2.

\begin{tabular}{lccc}
\hline Index coefficient & The early warning system used in this paper & Traditional early warning system & Actual data \\
\hline Transverse axis displacement 1 & 3.412 & 3.021 & 3.685 \\
Longitudinal axis displacement 1 & 3.104 & 6.892 & 3.334 \\
Z-axis displacement 1 & 7.225 & 4.822 & 7.212 \\
Total displacement 1 & 4.944 & 3.221 & 4.901 \\
Transverse axis displacement 2 & 3.312 & 2.585 & 3.321 \\
Longitudinal axis displacement 2 & 3.134 & 6.692 & 3.098 \\
Z-axis displacement 2 & 7.315 & 5.922 & 7.222 \\
Total displacement 2 & 5.944 & 3.021 & 5.801 \\
Transverse axis displacement 3 & 3.412 & 2.685 & 3.334 \\
Longitudinal axis displacement 3 & 3.104 & 6.892 & 3.043 \\
Z-axis displacement 3 & 7.225 & 4.822 \\
Total displacement 3 & 4.944 & & 7.212 \\
\hline
\end{tabular}

TABLe 4: Comparison of experimental data in area 3.

\begin{tabular}{lccc}
\hline Index coefficient & The early warning system used in this paper & Traditional early warning system & Actual data \\
\hline Transverse axis displacement 1 & 5.342 & 4.721 & 1.985 \\
Longitudinal axis displacement 1 & 2.321 & 7.902 & 2.299 \\
Z-axis displacement 1 & 8.125 & 2.812 & 8.301 \\
Total displacement 1 & 3.474 & 4.822 & 3.421 \\
Transverse axis displacement 2 & 5.344 & 2.985 & 5.374 \\
Longitudinal axis displacement 2 & 3.602 & 6.092 & 3.603 \\
Z-axis displacement 2 & 3.404 & 2.812 & 3.339 \\
Total displacement 2 & 6.225 & 4.822 & 6.119 \\
Transverse axis displacement 3 & 3.474 & 3.421 & 3.574 \\
Longitudinal axis displacement 3 & 5.344 & 2.985 \\
Z-axis displacement 3 & 3.602 & 3.321 \\
Total displacement 3 & 3.404 & 3.603 \\
\hline
\end{tabular}

TABLe 5: Comparison of experimental data in area 4.

\begin{tabular}{lccc}
\hline Index coefficient & The early warning system used in this paper & Traditional early warning system & Actual data \\
\hline Transverse axis displacement 1 & 6.225 & 6.092 & 4.822 \\
Longitudinal axis displacement 1 & 5.344 & 3.221 & 5.119 \\
Z-axis displacement 1 & 3.312 & 2.585 & 3.321 \\
Total displacement 1 & 3.134 & 4.822 & 3.098 \\
Transverse axis displacement 2 & 5.344 & 3.421 & 5.321 \\
Longitudinal axis displacement 2 & 3.602 & 2.985 & 3.603 \\
Z-axis displacement 2 & 3.404 & 6.092 & 3.339 \\
Total displacement 2 & 6.225 & 2.585 & 6.119 \\
Transverse axis displacement 3 & 3.134 & 6.692 & 3.098 \\
Longitudinal axis displacement 3 & 7.315 & 5.922 & 7.222 \\
Z-axis displacement 3 & 5.944 & 3.021 \\
Total displacement 3 & 3.412 & 5.801 \\
\hline
\end{tabular}

TABLE 6: Comparison of experimental data in area 5.

\begin{tabular}{lccc}
\hline Index coefficient & The early warning system used in this paper & Traditional early warning system & Actual data \\
\hline Transverse axis displacement 1 & 3.602 & 3.421 & 3.603 \\
Longitudinal axis displacement 1 & 3.404 & 2.985 & 3.092 \\
Z-axis displacement 1 & 6.225 & 2.585 & 6.119 \\
Total displacement 1 & 3.134 & 6.692 & 3.098 \\
Transverse axis displacement 2 & 7.315 & 5.783 \\
Longitudinal axis displacement 2 & 6.125 & 2.685 & 7.222 \\
Z-axis displacement 2 & 3.104 & 6.892 & 6.095 \\
Total displacement 2 & 7.225 & 6.892 & 3.043 \\
Transverse axis displacement 3 & 7.225 & 4.822 & 7.212 \\
Longitudinal axis displacement 3 & 4.944 & 3.221 \\
Z-axis displacement 3 & 3.312 & 6.712 \\
Total displacement 3 & 7.025 & 4.901 \\
\hline
\end{tabular}


TABLE 7: Comparison of experimental data in area 7.

\begin{tabular}{lccc}
\hline Index coefficient & $\begin{array}{c}\text { The early } \\
\text { warning system } \\
\text { used in this } \\
\text { paper }\end{array}$ & $\begin{array}{c}\text { Traditional early } \\
\text { warning system }\end{array}$ & $\begin{array}{c}\text { Actual } \\
\text { data }\end{array}$ \\
\hline $\begin{array}{l}\text { Transverse axis } \\
\text { displacement 1 }\end{array}$ & 4.678 & 3.921 & 4.573 \\
$\begin{array}{l}\text { Longitudinal axis } \\
\text { displacement 1 }\end{array}$ & 7.452 & 6.451 & 7.382 \\
$\begin{array}{l}Z \text {-axis } \\
\text { displacement 1 }\end{array}$ & 6.125 & 5.783 & 6.095 \\
$\begin{array}{l}\text { Total } \\
\text { displacement 1 }\end{array}$ & 3.944 & 2.912 & 3.844 \\
$\begin{array}{l}\text { Transverse axis } \\
\text { displacement 2 }\end{array}$ & 3.404 & 2.985 & 3.339 \\
$\begin{array}{l}\text { Longitudinal axis } \\
\text { displacement 2 }\end{array}$ & 6.125 & 5.783 & 6.095 \\
$\begin{array}{l}Z \text {-axis } \\
\text { displacement 2 }\end{array}$ & 6.025 & 5.493 & 6.005 \\
$\begin{array}{l}\text { Total } \\
\text { displacement 2 } \\
\text { Transverse axis } \\
\text { displacement 3 } \\
\begin{array}{l}\text { Longitudinal axis } \\
\text { displacement 3 }\end{array}\end{array}$ & 3.944 & 2.912 & 3.844 \\
$\begin{array}{l}Z \text {-axis } \\
\text { displacement 3 }\end{array}$ & 3.602 & 3.421 & 3.603 \\
$\begin{array}{l}\text { Total } \\
\text { displacement 3 }\end{array}$ & 3.134 & 2.985 & 3.339 \\
\hline
\end{tabular}

Based on the above experimental results, it can be verified that the visual early warning and monitoring system of surface deformation based on GIS has strong practicability and accuracy.

\section{Conclusion}

This paper mainly analyzes and studies the serious consequences of the surface deformation corresponding to the collapse area and analyzes the corresponding research status of the current monitoring and early warning of the surface deformation. At the same time, it is concluded that visualization and improving the accuracy of the natural disasters caused by the surface deformation are the important problems to be solved urgently. Based on this, based on GIS, this paper combines it with the surface subsidence analysis and comprehensively analyzes the surface subsidence, tilt value, curvature deformation value, horizontal movement, and corresponding horizontal deformation formula. In order to make the surface deformation visualization corresponding to the collapse area, this paper innovatively introduces the 3D visualization subsidence data analysis and realizes the calculation result analysis and corresponding retrieval multiple visualization in the process of subsidence area depth prediction. Based on this, this paper can realize the optimization analysis of the prediction data of the subsidence area and then grasp the efficient and accurate law of surface deformation. In the experimental part, a mine pit is taken as the experimental object, and the three-dimensional visual monitoring is carried out. The experimental results show that the prediction results and corresponding early warning accuracy of the system are significantly improved compared with the traditional scheme, which provides practical significance for disaster prevention and corresponding environmental impact assessment. The corresponding follow-up research in this paper will mainly focus on the electromagnetic leakage solution of $3 \mathrm{D}$ visualization technology and further analysis and research on the corresponding prediction accuracy. At the same time, the complex analysis of different rock composition and corresponding collapse causes in different areas will make the visualization software more universal, and further research and analysis are carried out in the aspects of software resource consumption and cost control.

\section{Data Availability}

The data used to support the findings of this study are available from the corresponding author upon request.

\section{Conflicts of Interest}

The authors declare that they have no conflicts of interest.

\section{Acknowledgments}

This study was supported by the Industrial Support and Guidance Project of Colleges and Universities in Gansu Province in 2019: Research and Key Technology of Coal Mine Reclamation in Gansu Province (no. 2019C-16).

\section{References}

[1] M. Zheng, K. Deng, H. Fan et al., "Monitoring and analysis of mining 3D time-series deformation based on multi-track SAR data," International Journal of Remote Sensing, vol. 40, no. 3, pp. 1411-1427, 2018.

[2] L. Weiguo, W. Xiaodong, W. Fenwei, and W. Haiyan, "Feature extraction and early warning of agglomeration in fluidized bed reactors based on an acoustic approach," Powder Technology, vol. 279, no. 4, pp. 185-195, 2015.

[3] X. Diao, K. Wu, D. Hu, L. Li, and D. Zhou, "Combining differential SAR interferometry and the probability integral method for three-dimensional deformation monitoring of mining areas," International Journal of Remote Sensing, vol. 37, no. 21, pp. 5196-5212, 2016.

[4] L. Liu, C. Wang, H. Zhang et al., "Automatic monitoring method for surface deformation of coastal area based on time series analysis," Journal of Coastal Research, vol. 93, no. 3, pp. 194-201, 2019.

[5] M. Fan and B. Carrapa, "Late cretaceous-early eocene laramide uplift, exhumation, and basin subsidence in Wyoming: crustal responses to flat slab subduction," Tectonics, vol. 33, no. 4, pp. 509-529, 2014.

[6] Z. Su, J.-C. Hu, E. Wang, Y. Li, Y. Yang, and P.-L. Wang, "Monitoring interseismic activity on the Ilan Plain (NE Taiwan) using small baseline PS-InSAR, GPS and leveling measurements: partitioning from arc-continent collision and backarc extension," Geophysical Journal International, vol. 212, no. 1, pp. 264-283, 2018.

[7] L. Wang, N. Li, N. Zhang et al., "Full parameters inversion model for mining subsidence prediction using simulated annealing based on single line of sight D-lnSAR," Environmental Earth Sciences, vol. 77, no. 5, pp. 161.1-161.11, 2018. 
[8] C. Ecker, A. Shahidiani, Y. Feng et al., "The effect of age, diagnosis, and their interaction on vertex-based measures of cortical thickness and surface area in autism spectrum disorder," Journal of Neural Transmission, vol. 121, no. 9, pp. 1157-1170, 2014.

[9] Y. Tang, Z. Qing, L. Zhu, and R. Zhang, "Study on the structural monitoring and early warning conditions of aging jacket platforms," Ocean Engineering, vol. 101, no. 1, pp. 152-160, 2015.

[10] J. Wang, P. Wang, Q. Qin, and H. Wang, "The effects of land subsidence and rehabilitation on soil hydraulic properties in a mining area in the Loess Plateau of China," CATENA, vol. 159, no. 5, pp. 51-59, 2017.

[11] G. Desir, F. Gutiérrez, J. Merino et al., "Rapid subsidence in damaging sinkholes: measurement by high-precision leveling and the role of salt dissolution," Geomorphology, vol. 303, no. 5, pp. 393-409, 2018.

[12] D. Carbonel, V. Rodríguez-Tribaldos, F. Gutiérrez et al., "Investigating a damaging buried sinkhole cluster in an urban area (Zaragoza city, NE Spain) integrating multiple techniques: geomorphological surveys, DInSAR, DEMs, GPR, ERT, and trenching," Geomorphology, vol. 229, no. 5, pp. 3-16, 2015.

[13] G. Yao, Q. Ke, J. Zhang et al., "Surface deformation monitoring of Shanghai based on ENVISAT ASAR and Sentinel-1A data," Environmental Earth Sciences, vol. 78, no. 6, pp. 11-17, 2019.

[14] P. Acero, L. F. Auqué, J. P. Galve et al., "Evaluation of geochemical and hydrogeological processes by geochemical modeling in an area affected by evaporite karstification," Journal of Hydrology, vol. 529, no. 5, pp. 1874-1889, 2015.

[15] I. Shennan, N. Barlow, R. Combellick, K. Pierre, and O. Stuart-Taylor, "Late holocene paleoseismology of a site in the region of maximum subsidence during the $1964 \mathrm{Mw} 9.2$ Alaska earthquake," Journal of Quaternary Science, vol. 29, no. 4, pp. 343-350, 2014.

[16] T. D. Bartholomew, T. A. Little, K. J. Clark, R. Van Dissen, and P. M. Barnes, "Kinematics and paleoseismology of the Vernon fault, Marlborough fault system, New Zealand: implications for contractional fault bend deformation, earthquake triggering, and the record of Hikurangi subduction earthquakes," Tectonics, vol. 33, no. 7, pp. 1201-1218, 2014.

[17] J. Zhang, Q. Sun, A. Fourie et al., "Risk assessment and prevention of surface subsidence in deep multiple coal seam mining under dense above-ground buildings: case study," Human and Ecological Risk Assessment, vol. 25, no. 5, pp. 1579-1593, 2019.

[18] Y. Liu, C. Zhao, Q. Zhang, and C. Yang, "Complex surface deformation monitoring and mechanism inversion over Qingxu-Jiaocheng, China with multi-sensor SAR images," Journal of Geodynamics, vol. 114, no. 6, pp. 41-52, 2018.

[19] A. Negredo, R. Sabadini, and C. Giunchi, "Interplay between subduction and continental convergence: a three-dimensional dynamic model for the Central Mediterranean," Geophysical Journal International, vol. 131, no. 1, pp. F9-F13, 2018.

[20] U. Dogan and A. Kocyigit, "Morphotectonic evolution of Mavibogaz canyon and Sugla Polje, SW central Anatolia, Turkey," Geomorphology, vol. 306, no. 1, pp. 13-27, 2018.

[21] D. Wu, J. Chen, J. Wang, X. He, M. Xin, and B. Wang, "Monitoring and warning of lipophilic marine algal toxins in mariculture zone based on toxin profiles of phytoplankton," Ecotoxicology and Environmental Safety, vol. 197, no. 6, p. 110647, 2020.

[22] R. Yousefian and S. Kamalasadan, "Design and real-time implementation of optimal power system wide-area system- centric controller based on temporal difference learning," IEEE Transactions on Industry Applications, vol. 52, no. 1, pp. 395-406, 2016.

[23] N. C. Cristea, I. Breckheimer, M. S. Raleigh, J. HilleRisLambers, and J. D. Lundquist, "An evaluation of terrain-based downscaling of fractional snow covered area data sets based on LiDAR-derived snow data and orthoimagery," Water Resources Research, vol. 53, no. 8, pp. 6802-6820, 2017.

[24] J. Xie, X. Han, C. Zong, H. Ji, and C. Lu, "Large-area patterning of polyaniline film based on in situ self-wrinkling and its reversible doping/dedoping tunability," Macromolecules, vol. 48, no. 3, pp. 663-671, 2015.

[25] O. Cros, H. Knutsson, M. Andersson, E. Pawels, M. Borga, and M. Gaihede, "Determination of the mastoid surface area and volume based on micro-CT scanning of human temporal bones. Geometrical parameters depend on scanning resolutions," Hearing Research, vol. 340, no. 4, pp. 127-134, 2016.

[26] W. Qu, Z. Lu, Q. Zhang et al., "Crustal deformation and strain fields of the Weihe Basin and surrounding area of central China based on GPS observations and kinematic models," Journal of Geodynamics, vol. 120, no. 10, pp. 1-10, 2018.

[27] C. Li-Qun, S. Yeboah, S. Cheng-Sheng, C. Xiao-Dong, and Z. Ren-Zhi, "GIS-based assessment of arable layer pollution of copper $(\mathrm{Cu})$, zinc $(\mathrm{Zn})$ and lead $(\mathrm{Pb})$ in Baiyin District of Gansu Province," Environmental Earth Sciences, vol. 74, no. 1, pp. 803-811, 2015.

[28] J. R. Adams, H. Mcnairn, A. A. Berg, and C. Champagne, "Evaluation of near-surface soil moisture data from an AAFC monitoring network in Manitoba, Canada: implications for L-band satellite validation," Journal of Hydrology, vol. 521, no. 3, pp. 582-592, 2015.

[29] I. A. Brigadnov, "Power law type Poynting effect and non-homogeneous radial deformation in the boundary-value problem of torsion of a nonlinear elastic cylinder," Acta Mechanica, vol. 226, no. 4, pp. 1309-1317, 2015.

[30] I. Povšič, M. Jezeršek, and J. Možina, "Real-time 3D visualization of the thoraco-abdominal surface during breathing with body movement and deformation extraction," Physiological Measurement, vol. 36, no. 7, pp. 1497-1516, 2015.

[31] G. Li, H. Yuan, and X. Ma, "Optimum design of the precise surface plate based on thermal deformation experiment and FEA," Journal of Thermal Stresses, vol. 37, no. 1, pp. 1-13, 2014.

[32] M. Zabihi, J. Shayegan, M. Fahimirad, and F. Khorasheh, "Preparation, characterization and kinetic behavior of supported copper oxide catalysts on almond shell-based activated carbon for oxidation of toluene in air," Journal of Porous Materials, vol. 22, no. 1, pp. 101-118, 2015.

[33] R. Béjaud, J. Durinck, and S. Brochard, "The effect of surface step and twin boundary on deformation twinning in nanoscale metallic systems," Computational Materials Science, vol. 145, no. 3, pp. 116-125, 2018.

[34] A. Asadollahi, S. Rashidi, A. Esfahani et al., "Simulating phase change during the droplet deformation and impact on a wet surface in a square microchannel: an application of oil drops collision," The European Physical Journal Plus, vol. 133, no. 8, pp. 306-312, 2018.

[35] N. Dreier and P. Fröhle, "Operational wave forecast in the German bight as part of a sensor- and risk based early warning system," Journal of Coastal Research, vol. 85, no. 3, pp. 1161-1165, 2018. 